\title{
Impact of the Staffing Structure of Intensive Care Units and High Care Units on In-Hospital Mortality Among Patients with Sepsis: A Retrospective Analysis of Japanese Nationwide Claims Data
}

\section{Kota Nishimoto}

Kansai Medical University Department of Anesthesiology: Kansai Ika Daigaku Masui Kagaku

Takeshi Umegaki ( $\square$ umegakit@hirakata.kmu.ac.jp )

Kansai Medical University Department of Anesthesiology: Kansai Ika Daigaku Masui Kagaku https://orcid.org/0000-0001-6113-6444

Takahiko Kamibayashi

Kansai Medical University Department of Anesthesiology: Kansai Ika Daigaku Masui Kagaku

Research

Keywords: National database, Donabedian model, sepsis, in-hospital mortality, critical care

Posted Date: August 13th, 2021

DOl: https://doi.org/10.21203/rs.3.rs-796517/v1

License: (c) (i) This work is licensed under a Creative Commons Attribution 4.0 International License.

Read Full License 


\section{Abstract}

Background: Critical care in Japan is provided in intensive care units (ICUs) and high care units (HCUs), which are categorized based on their fulfillment of different staffing criteria. Under Japan's medical fee reimbursement system, units with higher staffing levels are eligible to receive higher reimbursements. However, the different staffing structure of these units may affect the quality of care and patient outcomes. This study aimed to analyze the impact of ICU/HCU staffing structure on in-hospital mortality among septic patients in Japan's acute care hospitals using a nationwide claims database.

Methods: We conducted a large-scale multicenter retrospective cohort study of adult septic patients (aged $\geq 18$ years) who received critical care in acute care hospitals throughout Japan between April 2018 and March 2019. Patients were categorized into three groups according to the type of unit in which they received critical care: Type 1 ICUs (fulfilling stringent staffing criteria such as experienced intensivists and high nurse-to-patient ratios), Type 2 ICUs (fulfilling less stringent criteria), and HCUs (fulfilling the least stringent criteria). A Cox proportional hazards regression model was constructed with in-hospital mortality as the dependent variable and the ICU/HCU groups as the main independent variable of interest. Other covariates included age, emergency or non-emergency admission, major diagnostic categories, mechanical ventilation, noninvasive positive airway pressure ventilation, oxygen therapy, and renal replacement therapy.

Results: We analyzed 2411 patients (178 hospitals) in the Type 1 ICU group, 3653 patients (422 hospitals) in the Type 2 ICU group, and 4904 patients (521 hospitals) in the HCU group. When compared with the HCU group, the adjusted hazard ratios for in-hospital mortality were 0.74 ( $95 \%$ confidence interval: $0.71-0.77 ; P<0.001)$ for the Type 1 ICU group and $0.83(0.80-0.85 ; P<0.001)$ for the Type 2 ICU group. Emergency hospital admission had the highest hazard ratio for in-hospital mortality (hazard ratio: 4.78; $P<0.001)$.

Conclusions: ICUs that fulfill more stringent staffing criteria were associated with lower in-hospital mortality in septic patients than HCUs after adjusting for confounders. Optimizing the staffing structure of these units may contribute to the improvement of patient outcomes.

\section{Introduction}

Sepsis refers to a dysregulated host response to infection resulting in potentially fatal organ dysfunction [1], and is associated with heavy clinical and economic burdens throughout the world [2, 3]. Due to the high risk of rapid deterioration, this syndrome requires prompt and intensive treatment (e.g., antibiotic therapy, fluid resuscitation, and supplemental oxygen) [4]. Optimal sepsis care is therefore dependent on the availability of an effective health care provision system with adequate resources.

Donabedian's structure-process-outcome model is a well-established approach for assessing health care quality [5], and has been applied in the fields of critical care and emergency care [6-10]. The staffing characteristics of intensive care units (ICUs) can be analyzed as part of the "structure" component of 
Donabedian's triad. Among Japan's acute care hospitals, critical care is provided in ICUs and high care units (HCUs). While HCUs share some similarities in organization and function with the high-dependency units of other countries, many Japanese hospitals that lack ICUs treat critically ill patients in HCUs. The definitions of ICUs and HCUs are set by Japan's medical fee reimbursement system and are based on the units' staffing structure, such as the availability and experience of medical staff (Table 1). Under this system, ICUs are divided into two types, with Type 1 ICUs fulfilling more stringent staffing criteria and receiving higher reimbursements than Type 2 ICUs. Furthermore, both ICU types are entitled to receive higher reimbursements than HCUs, which fulfill less restrictive criteria. Despite these differences in staffing structure, studies have yet to explore the differences in the quality of care provided to septic patients among these units.

Table 1

Staffing criteria for ICU and HCU classifications under Japan's medical fee reimbursement system

$\begin{array}{lll}\text { Type } 1 \text { ICUs } & \text { Type } 2 \text { ICUs } & \text { HCUs } \\ \begin{array}{l}\text { Two or more dedicated intensivists } \\ \text { (each with } \geq 5 \text { years of experience in } \\ \text { critical care) always on duty }\end{array} & \begin{array}{l}\text { Dedicated } \\ \text { intensivist/physician } \\ \text { always on duty }\end{array} & \begin{array}{l}\text { Dedicated } \\ \text { intensivist/physician } \\ \text { always on duty }\end{array} \\ \begin{array}{l}\text { Minimum nurse-to-patient ratio of 1:2 } \\ \text { (Each nurse is assigned } \leq 2 \text { patients) }\end{array} & \begin{array}{l}\text { Minimum nurse-to-patient } \\ \text { ratio of 1:2 (Each nurse is } \\ \text { assigned } \leq 2 \text { patients) }\end{array} & \begin{array}{l}\text { Minimum nurse-to-patient } \\ \text { ratio of 1:5 (Each nurse is } \\ \text { assigned } \leq 5 \text { patients) }\end{array}\end{array}$

Dedicated nurse with $\geq 5$ years of nursing experience in critical care or $\geq$ 600 hours of critical care training; Works in the ICU for $\geq 20$ hours/week

Dedicated medical technologist always on duty within the hospital

Over $80 \%$ of admitted patients each month fulfill the evaluation criteria for medical and nursing care needs
Over $70 \%$ of admitted patients each month fulfill the evaluation criteria for medical and nursing care needs

\begin{abstract}
Over $60 \%$ of admitted patients each month fulfill the evaluation criteria for medical and nursing care needs
\end{abstract}

ICU intensive care unit, $\mathrm{HCU}$ high care unit

Insurance claims data comprise transactional records for episodes of care, and are widely used in health care research. In 2009, the National Database of Health Insurance Claims and Specific Health Checkups of Japan (NDB) was developed to collect and maintain claims data and medical checkup data from throughout the country. These data are formatted according to Japan's Diagnosis Procedure Combination (DPC) case-mix system, which dictates reimbursements for acute care hospitals. As of 2017, the NDB has acquired over $95 \%$ of Japan's total insurance claims [11]. However, the NDB has yet to be applied in critical care research. 
This study aimed to analyze the impact of the staffing structure of ICUs and HCUs on in-hospital mortality among septic patients in Japan's acute care hospitals.

\section{Methods}

\section{Study design and data source}

We conducted a multicenter retrospective observational study of adult patients with sepsis who were admitted to an ICU or HCU between April 1, 2018 and March 31, 2019. The patients were divided into three groups according to the unit in which they received critical care: Type 1 ICUs, Type 2 ICUs, and HCUs. In addition to staffing criteria, these units are also categorized based on the monthly proportion of admitted patients who fulfill specific evaluation criteria for medical and nursing care needs (Supplementary Table 1).

The data source was a DPC database extracted from the NDB. DPC data comprise clinical information and claims data, and include patient demographics (e.g., age, sex, height, and weight), primary and secondary diagnoses, dates of admission and discharge, comorbidities, treatments (e.g., mechanical ventilation, renal replacement therapy, and vasopressor administration), and discharge status. Details on ICU and HCU utilization are also included.

This study was approved by the institutional review board of Kansai Medical University Hospital (Approval number: 2019078), and was registered at Japan's University Hospital Medical Information Network Clinical Trials Registry (ID: UMIN000044371).

\section{Patient selection}

Septic patients were identified as those with the relevant International Classification of Diseases, 10th Revision codes upon admission or during hospitalization (Table 2). The dates of ICU/HCU admission were determined based on Japanese treatment codes provided in the claims data. We excluded patients who were not yet discharged from hospital during the study period, patients aged below 18 years, and patients with missing age data. 
Table 2

ICD-10 codes used for the identification of sepsis

\begin{tabular}{|c|c|c|c|}
\hline Condition & $\begin{array}{l}\text { ICD-10 } \\
\text { code }\end{array}$ & Condition & $\begin{array}{l}\text { ICD-10 } \\
\text { code }\end{array}$ \\
\hline Sepsis due to streptococcus, group A & A400 & Bacillus cereus sepsis & A418 \\
\hline Sepsis due to streptococcus, group B & A401 & Anthrax sepsis & A227 \\
\hline Sepsis due to streptococcus, group C & A408 & Enterococcal sepsis & A418 \\
\hline Sepsis due to streptococcus, group D & A402 & $\begin{array}{l}\text { Streptococcus pneumoniae } \\
\text { sepsis }\end{array}$ & A403 \\
\hline Sepsis due to streptococcus, group G & A408 & Sepsis & A419 \\
\hline $\begin{array}{l}\text { Methicillin-resistant coagulase-negative } \\
\text { staphylococci }\end{array}$ & A411 & Septic pharyngitis & J020 \\
\hline Methicillin-resistant Staphylococcus aureus & A410 & Septic bronchitis & J209 \\
\hline Hospital-acquired sepsis & A419 & Septic osteomyelitis & M8699 \\
\hline Haemophilus influenzae sepsis & A413 & Septic shock & A419 \\
\hline Viral sepsis & B349 & Septic endocarditis & 1330 \\
\hline Yersinia sepsis & A282 & Septic pericarditis & 1301 \\
\hline Staphylococcus aureus sepsis & A410 & Septic abscess & L029 \\
\hline Catheter-related sepsis & T814 & Septic pneumonia & A419 \\
\hline Candida sepsis & B377 & Septic dermatitis & L080 \\
\hline $\begin{array}{l}\text { Sepsis due to other gram-negative } \\
\text { organisms }\end{array}$ & A415 & Septic gangrene & A419 \\
\hline Gram-negative sepsis & A415 & Streptococcal sepsis & A412 \\
\hline Gram-positive sepsis & A418 & Sepsis during labor & 0753 \\
\hline Anaerobic sepsis & A414 & Herpesviral sepsis & B007 \\
\hline Coagulase-negative staphylococcal sepsis & A411 & Actinomycotic sepsis & A427 \\
\hline Salmonella sepsis & A021 & Septicemic plague & A207 \\
\hline Obstetric septic embolism & 0883 & Streptococcal sepsis & A409 \\
\hline Postpartum sepsis & 085 & Listerial sepsis & A327 \\
\hline Progressive septic granulomatosis & D71 & Gonococcal sepsis & A548 \\
\hline Postoperative sepsis & T814 & Erysipelothrix sepsis & A267 \\
\hline
\end{tabular}




\begin{tabular}{|lccc|}
\hline Condition & $\begin{array}{l}\text { ICD-10 } \\
\text { code }\end{array}$ & Condition & $\begin{array}{l}\text { ICD-10 } \\
\text { code }\end{array}$ \\
\hline Meningococcal sepsis & A394 & Acute fulminant sepsis & A241 \\
\hline$I C D-10$ International Classification of Diseases, & Tenth Revision & \\
\hline Patient characteristics and treatments & \\
\hline
\end{tabular}

We collected information on the following patient baseline characteristics: age, sex, hospital admission course (emergency or non-emergency), and major diagnostic category. Furthermore, the use of mechanical ventilation, noninvasive positive pressure ventilation, high-flow oxygen therapy, renal replacement therapy, endotoxin absorption, tracheotomy, adrenaline, noradrenaline, and vasopressin were identified from the corresponding Japanese procedural codes. Patients with acute respiratory distress syndrome (ARDS) were identified using the International Classification of Diseases, 10 th Revision code J80.

\section{Outcome measures}

The study's primary outcome measure was in-hospital mortality, and the secondary outcome measures were ICU/HCU stay (days) and overall hospital stay (days).

\section{Statistical analysis}

Continuous variables were calculated as means and standard deviations, and categorical variables were calculated as numbers and percentages. One-way analysis of variance and the Chi-squared test were used to compare the continuous and categorical variables, respectively, among the three ICU/HCU groups (Type 1 ICUs, Type 2 ICUs, and HCUs). We plotted Kaplan-Meier survival curves to examine the differences in survival among the three groups.

Univariate analyses were performed to identify patient characteristics and treatments that were significantly associated $(P<0.05)$ with in-hospital mortality; these characteristics were included as covariates in a Cox proportional hazards regression model with in-hospital mortality as the dependent variable and the ICU/HCU groups as the main independent variable of interest. The hazard ratios (HRs) and $95 \%$ confidence intervals (Cls) were calculated for the independent variables. In addition, subgroup analyses were performed for patients with (a) sepsis-induced ARDS, (b) sepsis induced by methicillinresistant Staphylococcus aureus (MRSA), and (c) sepsis with blood, blood-forming organs, and immunological disorders.

$P$ values lower than 0.05 were considered to be statistically significant. All analyses were performed using SPSS Version 26.0 (IBM Japan, Ltd., Tokyo, Japan).

\section{Results}


Figure 1 shows the flowchart of patient selection. From among 671,425 patients admitted to an ICU or HCU in 900 hospitals, we identified 32,690 patients with a recorded diagnosis of sepsis. We then excluded 19,956 patients who were not discharged during the study period, 161 patients aged below 18 years, and 1605 patients with missing age data. The final analysis was conducted using 10,968 patients in 861 hospitals. Of these, 2411 patients ( 178 hospitals) were treated in a Type 1 ICU, 3653 patients (422 hospitals) were treated in a Type 2 ICU, and 4904 patients (521 hospitals) were treated in an HCU.

The patient characteristics and treatments are summarized in Table 3. The mean ages of the patients in the Type 1 ICU group, Type 2 ICU group, and HCU group were 72.1 years, 73.6 years and 76.8 years, respectively $(P<0.001)$. There were also significant intergroup differences in sex and emergency admissions. In all groups, men accounted for the majority of patients, and emergency admissions comprised more than $80 \%$ of cases. Among the treatments, the use of mechanical ventilation was significantly higher $(P<0.001)$ in the Type $1 \mathrm{ICU}$ group (58.4\%) and Type $2 \mathrm{ICU}$ group $(55.0 \%)$ than in the HCU group (28.2\%). However, there was no significant intergroup difference $(P=0.11)$ in the duration of mechanical ventilation. High-flow oxygen therapy was used more often than noninvasive positive pressure ventilation in all three groups. The use of tracheotomy was significantly higher $(P<0.001)$ in the Type 1 ICU group (5.1\%) than in the HCU group (1.7\%). Similarly, the use of renal replacement therapy was significantly higher $(P<0.001)$ in the Type 1 ICU group $(36.3 \%)$ and Type 2 ICU group $(31.7 \%)$ than in the HCU group (14.4\%). Furthermore, the use of endotoxin adsorption was significantly higher $(P<0.001)$ in the Type 1 ICU group (5.2\%) and Type 2 ICU group (3.9\%) than in the HCU group (2.2\%). Noradrenaline was administered to the majority of patients in the Type 1 ICU group (75.8\%) and Type 2 ICU group (70.7\%), but to less than half of all patients in the HCU group $(46 \%)(P<0.001)$. 
Table 3

Patient characteristics, treatments, and outcomes $(n=10,968)$

\begin{tabular}{|c|c|c|c|c|}
\hline Variables & $\begin{array}{l}\text { Type } 1 \text { ICUs } \\
(n=2411)\end{array}$ & $\begin{array}{l}\text { Type } 2 \text { ICUs } \\
(n=3653)\end{array}$ & $\begin{array}{l}\text { HCUs } \\
(n=4904)\end{array}$ & $P$ value \\
\hline Number of hospitals & 178 & 422 & 521 & - \\
\hline \multicolumn{5}{|l|}{ Patient characteristics } \\
\hline Age (years) & $72.1 \pm 13.8$ & $73.6 \pm 13.2$ & $76.8 \pm 12.7$ & $<0.001$ \\
\hline Male & $1469(60.9)$ & $2209(60.5)$ & $2795(57.0)$ & 0.001 \\
\hline \multicolumn{5}{|l|}{ Hospital admission course } \\
\hline Emergency & $2022(83.9)$ & $3168(86.7)$ & $4460(90.9)$ & $<0.001$ \\
\hline \multicolumn{5}{|l|}{ Treatments } \\
\hline Mechanical ventilation & $1409(58.4)$ & $2009(55.0)$ & $1381(28.2)$ & $<0.001$ \\
\hline Mechanical ventilation duration (days) & $6.3 \pm 5.9$ & $6.1 \pm 5.9$ & $6.6 \pm 6.5$ & 0.11 \\
\hline NPPV & $46(1.9)$ & $81(2.2)$ & $61(1.2)$ & $<0.01$ \\
\hline NPPV duration (days) & $5.7 \pm 6.2$ & $3.6 \pm 3.9$ & $5.6 \pm 5.3$ & 0.02 \\
\hline High-flow oxygen therapy & $186(7.7)$ & $227(6.2)$ & $174(3.5)$ & $<0.001$ \\
\hline High-flow oxygen therapy duration (days) & $3.4 \pm 3.3$ & $3.7 \pm 3.5$ & $4.1 \pm 3.7$ & 0.17 \\
\hline Renal replacement therapy & $875(36.3)$ & $1,159(31.7)$ & 707 (14.4) & $<0.001$ \\
\hline Renal replacement therapy duration (days) & $5.9 \pm 4.5$ & $5.6 \pm 4.3$ & $5.2 \pm 4.1$ & $<0.01$ \\
\hline Endotoxin adsorption & $125(5.2)$ & $143(3.9)$ & $106(2.2)$ & $<0.001$ \\
\hline Endotoxin adsorption (times) & $1.6 \pm 0.7$ & $1.7 \pm 0.8$ & $1.6 \pm 0.6$ & 0.33 \\
\hline Tracheotomy & $123(5.1)$ & $118(3.2)$ & $84(1.7)$ & $<0.001$ \\
\hline Adrenaline & $518(21.5)$ & $706(19.3)$ & $427(8.7)$ & $<0.001$ \\
\hline Adrenaline duration (days) & $1.6 \pm 1.7$ & $1.6 \pm 1.5$ & $1.4 \pm 1.3$ & 0.02 \\
\hline Noradrenaline & $1827(75.8)$ & $2581(70.7)$ & $2256(46.0)$ & $<0.001$ \\
\hline Noradrenaline duration (days) & $4.1 \pm 4.2$ & $4.0 \pm 4.2$ & $3.4 \pm 3.5$ & $<0.001$ \\
\hline Vasopressin & $625(25.9)$ & $674(18.5)$ & $272(5.5)$ & $<0.001$ \\
\hline
\end{tabular}

Values are presented as mean \pm standard deviation for continuous variables and number (percentage) for categorical variables.

ICU intensive care unit; $H C U$ high care unit; NPPV noninvasive positive pressure ventilation 


\begin{tabular}{|lllll|}
\hline Variables & $\begin{array}{l}\text { Type 1 ICUs } \\
(\mathbf{n = 2 4 1 1 )}\end{array}$ & $\begin{array}{l}\text { Type 2 ICUs } \\
(\mathbf{n = 3 6 5 3 )}\end{array}$ & $\begin{array}{l}\text { HCUs } \\
(\mathbf{n}=\mathbf{4 9 0 4})\end{array}$ & Pvalue \\
\hline Vasopressin duration (days) & $2.5 \pm 2.3$ & $2.5 \pm 2.4$ & $2.5 \pm 2.7$ & 0.97 \\
\hline Outcomes & & & & \\
\hline ICU/HCU stay (days) & $4.5 \pm 3.5$ & $4.2 \pm 3.4$ & $4.3 \pm 3.9$ & 0.05 \\
\hline Survivors & $3.7 \pm 2.8$ & $3.4 \pm 2.8$ & $3.7 \pm 3.3$ & $<0.01$ \\
\hline Non-survivors & $5.3 \pm 4.0$ & $5.1 \pm 3.9$ & $5.4 \pm 4.5$ & 0.07 \\
\hline Overall hospital stay (days) & $23.1 \pm 23.8$ & $22.3 \pm 21.9$ & $22.0 \pm 21.3$ & 0.12 \\
\hline Survivors & $25.2 \pm 22.6$ & $24.3 \pm 19.9$ & $22.9 \pm 20.3$ & $<0.01$ \\
\hline Non-survivors & $20.7 \pm 24.8$ & $20.3 \pm 23.7$ & $20.4 \pm 22.7$ & 0.91 \\
\hline In-hospital mortality & $1116(46.3)$ & $1772(48.5)$ & $1847(37.7)$ & $<0.001$ \\
\hline $\begin{array}{l}\text { Values are presented as mean } \pm \text { standard deviation for continuous variables and number (percentage) } \\
\text { for categorical variables. }\end{array}$ & & & \\
\hline ICU intensive care unit; $H C U$ high care unit; NPPVnoninvasive positive pressure ventilation & \\
\hline
\end{tabular}

Table 3 also presents the outcomes of each group. There was no significant difference $(P=0.05)$ in ICU/HCU stay among the groups (mean \pm standard deviation: $4.5 \pm 3.5$ days in the Type 1 ICU group, $4.2 \pm$ 3.4 days in the Type 2 ICU group, and $4.3 \pm 3.9$ days in the HCU group). There was also no significant difference $(P=0.12)$ in overall hospital stay among the groups (mean \pm standard deviation: $23.1 \pm 23.8$ days in the Type 1 ICU group, $22.3 \pm 21.9$ days in the Type 2 ICU group, and $22.0 \pm 21.3$ days in the HCU group). However, there was a significant difference $(P<0.001)$ in unadjusted in-hospital mortality among the groups (46.3\% in the Type 1 ICU group, $48.5 \%$ in the Type 2 ICU group, and $37.7 \%$ in the HCU group).

Table 4 presents the major diagnostic categories of the patients. In all groups, the most prevalent category was "digestive system, hepatobiliary system, and pancreas". This was followed by "circulatory system", "respiratory system", and "blood, blood-forming organs, and immunological disorders". 
Table 4

Major diagnostic categories of patients $(n=10,968)$

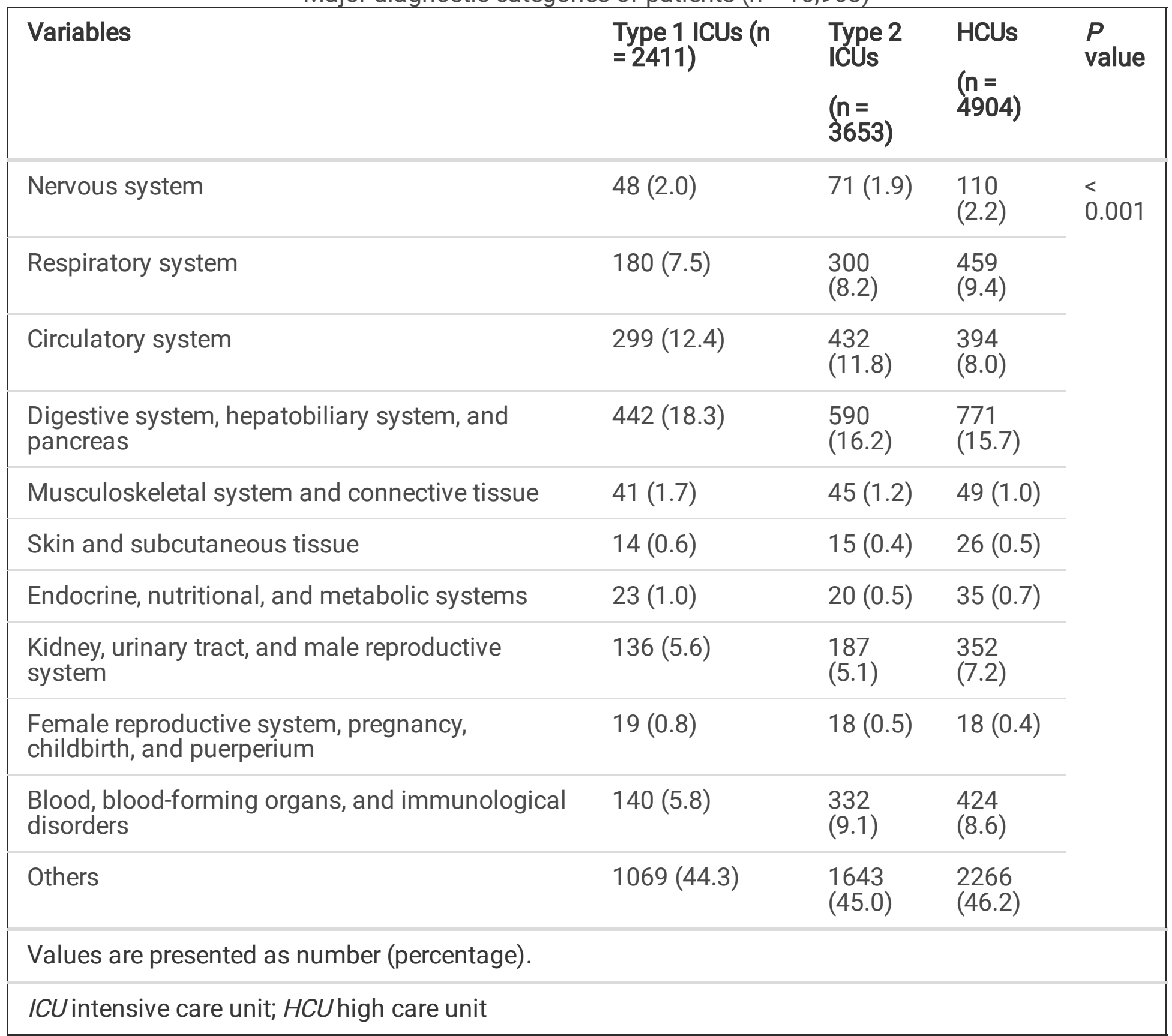

The unadjusted Kaplan-Meier survival curves for the three groups are shown in Fig. 2. There were significant differences in survival between the three groups (Type 1 ICU group versus Type 2 ICU group, $P$ = 0.04; Type $1 \mathrm{ICU}$ group versus HCU group, $P<0.001$; and Type $2 \mathrm{ICU}$ group versus HCU group, $P<0.001$ ). Before statistical adjustment, the HCU group had the highest survival rate. However, the two ICU groups had higher survival rates than the HCU group after adjusting for the covariates using the Cox proportional hazards model (Type 1 ICU group versus Type 2 ICU group, $P<0.001$; Type 1 ICU group versus HCU group, $P<0.001$; and Type 2 ICU group versus HCU group, $P<0.001$ ) (Fig. 3 ). The results of the Cox proportional hazards analysis of in-hospital mortality are provided in Table 5 . The ICU/HCU groups were significantly associated with in-hospital mortality after adjusting for the covariates $(P<0.001)$. When compared with the HCU group, the HRs for in-hospital mortality were 0.74 (95\% Cl: $0.71-0.77 ; P<0.001)$ for the Type 1 
ICU group and 0.83 (95\% Cl: $0.80-0.85 ; P<0.001)$ for the Type 2 ICU group. Emergency hospital admission had the highest hazard ratio for in-hospital mortality (hazard ratio: $4.78 ; P<0.001$ ). 
Table 5

Results of the Cox proportional hazards analysis for in-hospital mortality $(n=10,968)$

\begin{tabular}{|c|c|c|c|}
\hline Variables & $\begin{array}{l}\text { Hazard } \\
\text { ratio }\end{array}$ & $95 \% \mathrm{Cl}$ & $\begin{array}{l}P \\
\text { value }\end{array}$ \\
\hline Group (reference: HCUs) & & & $\dot{0} 001$ \\
\hline Type 1 ICUs & 0.74 & $\begin{array}{l}0.71- \\
0.77\end{array}$ & $\dot{0} 001$ \\
\hline Type 2 ICUs & 0.83 & $\begin{array}{l}0.80- \\
0.85\end{array}$ & $\dot{0} 001$ \\
\hline Age & 1.03 & $\begin{array}{l}1.03- \\
1.03\end{array}$ & $\dot{0} 001$ \\
\hline Male (reference: female) & 1.01 & $\begin{array}{l}0.98- \\
1.04\end{array}$ & 0.50 \\
\hline Emergency hospital admission (reference: non-emergency) & 4.78 & $4.57-5.00$ & $\dot{0} 001$ \\
\hline Major diagnostic category (reference: nervous system) & & & $\begin{array}{l}< \\
0.001\end{array}$ \\
\hline Respiratory system & 1.09 & $\begin{array}{l}0.53- \\
2.23\end{array}$ & 0.82 \\
\hline Circulatory system & 1.03 & $\begin{array}{l}0.52- \\
2.02\end{array}$ & 0.94 \\
\hline Digestive system, hepatobiliary system, and pancreas & 0.89 & $\begin{array}{l}0.41- \\
1.93\end{array}$ & 0.76 \\
\hline Musculoskeletal system and connective tissue & 1.61 & $\begin{array}{l}0.66- \\
3.92\end{array}$ & 0.30 \\
\hline Skin and subcutaneous tissue & - & - & 0.97 \\
\hline Endocrine, nutritional, and metabolic systems & - & - & 0.95 \\
\hline Kidney, urinary tract, and male reproductive system & 0.45 & $\begin{array}{l}0.17- \\
1.19\end{array}$ & 0.11 \\
\hline $\begin{array}{l}\text { Female reproductive system, pregnancy, childbirth, and } \\
\text { puerperium }\end{array}$ & - & - & 0.98 \\
\hline Blood, blood-forming organs, and immunological disorders & 1.62 & $\begin{array}{l}0.79- \\
3.32\end{array}$ & 0.18 \\
\hline Others & 1.60 & $\begin{array}{l}0.83- \\
3.06\end{array}$ & 0.16 \\
\hline
\end{tabular}

$\mathrm{Cl}$ confidence interval; $\mathrm{HCU}$ high care unit; ICU intensive care unit; NPPV noninvasive positive pressure ventilation 


\begin{tabular}{|c|c|c|c|}
\hline Variables & $\begin{array}{l}\text { Hazard } \\
\text { ratio }\end{array}$ & $95 \% \mathrm{Cl}$ & $\begin{array}{l}P \\
\text { value }\end{array}$ \\
\hline Mechanical ventilation & 1.62 & $\begin{array}{l}1.27- \\
2.07\end{array}$ & $\begin{array}{l}< \\
0.001\end{array}$ \\
\hline NPPV & 0.63 & $\begin{array}{l}0.30- \\
1.30\end{array}$ & 0.21 \\
\hline High-flow oxygen therapy & 1.07 & $\begin{array}{l}0.70- \\
1.65\end{array}$ & 0.75 \\
\hline Renal replacement therapy & 1.34 & $\begin{array}{l}1.06- \\
1.68\end{array}$ & 0.02 \\
\hline Endotoxin adsorption & 1.11 & $\begin{array}{l}0.57- \\
2.17\end{array}$ & 0.75 \\
\hline Tracheotomy & 0.87 & $\begin{array}{l}0.59- \\
1.30\end{array}$ & 0.50 \\
\hline Adrenaline & 1.51 & $\begin{array}{l}1.19- \\
1.92\end{array}$ & 0.001 \\
\hline Noradrenaline & 1.91 & $\begin{array}{l}1.47- \\
2.48\end{array}$ & $\begin{array}{l}< \\
0.001\end{array}$ \\
\hline Vasopressin & 0.94 & $\begin{array}{l}0.71- \\
1.23\end{array}$ & 0.63 \\
\hline
\end{tabular}

The subgroup analysis results are provided in Table 6 . When the samples were limited to sepsis-induced ARDS $(n=1395)$ or MRSA-induced sepsis $(n=760)$, the ICU/HCU groups were not significantly associated with in-hospital mortality (sepsis-induced ARDS: $P=0.12$; MRSA-induced sepsis: $P=0.10$ ). However, ICU/HCU groups remained a significant determinant of in-hospital mortality for cases of sepsis with blood, blood-forming organs, and immunological disorders $(\mathrm{n}=896 ; P<0.001)$. 
Table 6

Subgroup analysis results of the Cox proportional hazards analysis for in-hospital mortality

\begin{tabular}{|c|c|c|c|}
\hline Variables & $\begin{array}{l}\text { Hazard } \\
\text { ratio }\end{array}$ & $95 \% \mathrm{Cl}$ & $\begin{array}{l}P \\
\text { value }\end{array}$ \\
\hline \multicolumn{4}{|c|}{ Sepsis-induced ARDS $(n=1395)$} \\
\hline Group (reference: HCUs) & & & 0.12 \\
\hline Type 1 ICUs & 0.85 & $\begin{array}{l}0.70- \\
1.03\end{array}$ & 0.09 \\
\hline Type 2 ICUs & 1.03 & $\begin{array}{l}0.88- \\
1.20\end{array}$ & 0.73 \\
\hline \multicolumn{4}{|c|}{ MRSA-induced sepsis $(n=760)$} \\
\hline Group (reference: HCUs) & & & 0.10 \\
\hline Type 1 ICUs & 0.73 & $\begin{array}{l}0.55- \\
0.98\end{array}$ & 0.04 \\
\hline Type 2 ICUs & 0.84 & $\begin{array}{l}0.65- \\
1.08\end{array}$ & 0.16 \\
\hline \multicolumn{4}{|c|}{$\begin{array}{l}\text { Sepsis due to blood, blood-forming organs, and immunological } \\
\text { disorders }(n=896)\end{array}$} \\
\hline Group (reference: HCUs) & & & $\begin{array}{l}< \\
0.001\end{array}$ \\
\hline Type 1 ICUs & 0.60 & $\begin{array}{l}0.45- \\
0.81\end{array}$ & 0.001 \\
\hline Type 2 ICUs & 0.70 & $\begin{array}{l}0.57- \\
0.87\end{array}$ & 0.001 \\
\hline
\end{tabular}

\section{Discussion}

In this large-scale analysis of national-level claims data, we comparatively examined in-hospital mortality in septic patients among ICUs and HCUs designated by Japan's medical fee reimbursement system. Both ICU types were associated with significantly reduced hazards of in-hospitality mortality when compared to HCUs, with Type 1 ICUs (fulfilling more stringent staffing criteria) demonstrating a lower hazard than Type 2 ICUs.

In 2015, the American College of Critical Care Medicine Task Force on Models of Critical Care recognized that improvements in ICU structure can lead to better patient outcomes, and noted that a dedicated intensivist-led multidisciplinary team is integral to the effective delivery of critical care [12]. ICUs can be 
categorized as "open" or "closed", with the key difference being that only ICU intensivists can direct care and write medical orders in a closed ICU $[13,14]$. A US study reported that closed ICUs were associated with lower mortality in patients with acute lung injury [15]. Similarly, a Japanese study of septic patients found that closed ICUs were associated with increased survival and shorter ICU stays when compared with open ICUs [16]. A meta-analysis of open and closed ICUs also found that the former had significantly higher mortality rates than the latter for a variety of health conditions [17]. In our study, ICU/HCU staffing structure was determined based on staffing criteria. However, we could not ascertain the actual staffing numbers or the authority of intensivists in each unit, and were therefore unable to determine if each unit operated in an open or closed format. Nevertheless, the medical fee reimbursement system provides objective criteria that enabled us to categorize the ICUs and HCUs according to staffing factors. These criteria include the experience of intensivists and ICU nurses, as well as the availability of specialist staff. Our analysis detected significant differences in in-hospital mortality among the unit types, suggesting that the presence of dedicated intensivists, nurses, and medical technologists in critical care units can contribute to improved patient outcomes. These findings are consistent with those of previous studies on the staffing structure of critical care [12,15-17].

Among our subjects, mortality was particularly high in septic patients with blood, blood-forming organs, and immunological disorders. This corroborates the results of a previous study where hematological malignancies were associated with an increased hazard for sepsis and one-year mortality [18]. Another study reported an association between hematological malignancies and higher 28-day mortality in septic patients requiring ICU admission [19]. Our present study found that treatment in Type 1 ICUs was associated with reduced in-hospital mortality for such patients, suggesting that higher staffing levels with more experienced specialists can affect outcomes even in severe cases with blood and immunological disorders.

Previous studies have shown that ICU structural factors are also associated with other processes and outcomes of care. For example, staffing characteristics (including the presence of expert intensivists and dedicated pharmacists) have been linked with shorter mechanical ventilation durations [20]. Furthermore, regular examinations by intensivists in ICUs were found to be associated with the achievement of lighter sedation goals [21]. Another study determined that nurse-driven weaning from mechanical ventilation significantly reduced ventilation durations and ICU stay without adverse effects [22]. In contrast to those previous studies, our analysis found no significant differences in mechanical ventilation duration among the ICU/HCU groups. This may be because our observational study was based on staffing criteria, and did not account for the actual treatment strategies employed for each case. The presence and distribution of staff alone may not directly affect mechanical ventilation strategies in Japan's ICUs and HCUs, but further research is needed to explore this relationship.

This study has several limitations. First, there was a lack of information on each patient's blood examination results. Due to the lack of physiological data in the DPC database, we could not assess indicators such as leukocyte count, C-reactive protein levels, oxygenation levels, and blood pressure. Second, we could not compare Sequential Organ Failure Assessment scores among the groups because 
these were only introduced into the DPC system in 2018. At present, only Type 1 ICUs are required to record these scores, resulting in uneven records from Type 2 ICUs and HCUs. In addition, we did not have access to patients' comorbidities, and could not account for their variations. Nevertheless, we were able to include major diagnostic categories in our analytical models. Third, our analysis was dependent on the accuracy of the DPC records, which may include cases of upcoding or miscoding. However, these claims are submitted to insurers for reimbursements, and are therefore subject to stringent assessments for accuracy. Finally, our ICU/HCU groups were categorized based on staffing criteria, but we did not have any information on hospital size, staffing numbers, or ICU/HCU bed numbers. As a result, we could not determine the physician-to-patient ratio in each unit. It has been reported that an intensivist-to-patient ratio below 1:14 can detrimentally affect medical education, staff well-being, and patient care in ICUs [23].

\section{Conclusions}

This nationwide study is, to the best of our knowledge, the first to observe that the staffing structure of ICUs and HCUs is associated with in-hospital mortality in septic patients in Japan. The medical fee reimbursement system's staffing criteria for these and other hospital units may be associated with patient prognoses. Analyzing and optimizing the staffing structure of these units may contribute to the improvement of patient outcomes.

\section{Abbreviations}

ARDS

Acute respiratory distress syndrome; Cl:Confidence interval; DPC:Diagnosis Procedure Combination; HCU:High care unit; HR, Hazard ratio; ICU:Intensive care unit; MRSA:Methicillin-resistant Staphylococcus aureus, NDB:National Database of Health Insurance Claims and Specific Health Checkups of Japan

\section{Declarations}

\section{Acknowledgements}

We are grateful to the National Database of Health Insurance Claims and Specific Health Checkups of Japan for providing the data.

\section{Author contributions}

$\mathrm{KN}, \mathrm{TU}$, and TK conceptualized the study. KN and TU collected the data. TU performed data cleaning and statistical analysis. All authors interpreted the analytical results. KN and TU drafted the manuscript, and all authors critically revised the manuscript for important intellectual content. All authors read and approved the final version of the manuscript.

\section{Funding}


This research did not receive any funding from agencies in the public, commercial, or not-for-profit sectors.

\section{Availability of data and materials}

The data set used in this study is available from the corresponding author on reasonable request.

\section{Ethics approval and consent to participate}

This study was conducted in accordance with the principles of the Declaration of Helsinki, and was approved by the institutional review board of Kansai Medical University Hospital (Approval Number: 2019078). The requirement for informed consent from patients was waived given the retrospective design of the study and the use of anonymized patient and hospital data.

\section{Consent for publication}

Not applicable.

\section{Competing interests}

The authors declare that they have no competing interests.

\section{References}

1. Singer M, Deutschman CS, Seymour CW, Shankar-Hari M, Annane D, Bauer M, et al. The Third International Consensus Definitions for Sepsis and Septic Shock (Sepsis-3). JAMA. 2016;315:80110.

2. Prest J, Sathananthan M, Jeganathan N. Current trends in sepsis-related mortality in the United States. Crit Care Med. 2021;49:1276-84.

3. Rudd KE, Johnson SC, Agesa KM, Shackelford KA, Tsoi D, Kievlan DR, et al. Global, regional, and national sepsis incidence and mortality, 1990-2017: analysis for the Global Burden of Disease Study. Lancet. 2020;395:200-11.

4. Polat G, Ugan RA, Cadirci E, Halici Z. Sepsis and septic shock: Current treatment strategies and new approaches. Eurasian J Med. 2017;49:53-8.

5. Donabedian A. Evaluating the quality of medical care. Milbank Mem Fund Q. 1966;44:166-206.

6. Binder C, Torres RE, Elwell D. Use of the Donabedian Model as a Framework for COVID-19 Response at a Hospital in Suburban Westchester County, New York: A Facility-Level Case Report. J Emerg Nurs. 2021; 47: 239 - 55.

7. Ssemugabo C, Nalinya S, Halage AA, Neebye RM, Musoke D, Jørs E. Doctors experiences on the quality of care for pesticide poisoning patients in hospitals in Kampala, Uganda: a qualitative exploration using donabedian's model. BMC Health Serv Res. 2020;20:30. 
8. Algurén B, Jernberg T, Vasko P, Selb M, Coenen M. Content comparison and person-centeredness of standards for quality improvement in cardiovascular health care. PLoS One. 2021;16:e0244874.

9. Tossaint-Schoenmakers R, Versluis A, Chavannes N, Talboom-Kamp E, Kasteleyn M. The Challenge of Integrating eHealth Into Health Care: Systematic Literature Review of the Donabedian Model of Structure, Process, and Outcome. J Med Internet Res. 2021;23:e27180.

10. Santry HP, Strassels SA, Ingraham AM, Oslock WM, Ricci KB, Paredes AZ, et al. Identifying the fundamental structures and processes of care contributing to emergency general surgery quality using a mixed-methods Donabedian approach. BMC Med Res Methodol. 2020;20:247.

11. NDB open data |. Ministry of Health Labour and Welfare [Internet]. [cited 2021 Jul 11]. Available from: https://www.mhlw.go.jp/file/06-Seisakujouhou-12400000-Hokenkyoku/0000193322.pdf.

12. Weled BJ, Adzhigirey LA, Hodgman TM, Brilli RJ, Spevetz A, Kline AM, et al. Critical Care Delivery: The Importance of Process of Care and ICU Structure to Improved Outcomes: An Update From the American College of Critical Care Medicine Task Force on Models of Critical Care. Crit Care Med. 2015;43:1520-5.

13. Brilli RJ, Spevetz A, Branson RD, Campbell GM, Cohen H, Dasta JF, et al. The American College of Critical Care Medicine Guidelines for the Definition of an Intensivist and the Practice of Critical Care Medicine. Critical care delivery in the intensive care unit: defining clinical roles and the best practice model. Crit Care Med. 2001;29:2007-19.

14. Carlson RW, Weiland DE, Srivathsan K. Does a full time, 24-hour intensivist improve care and efficacy? Crit Care Clin. 1996;12:525-51.

15. Treggiari MM, Martin DP, Yanez ND, Caldwell E, Hudson LD, Rubenfeld GD. Effect of intensive care unit organizational model and structure on outcomes in patients with acute lung injury. Am J Respir Crit Care Med. 2007; 176: 685 - 90.

16. Ogura T, Nakamura Y, Takahashi K, Nishida K, Kobayashi D, Matsui S. Treatment of patients with sepsis in a closed intensive care unit is associated with improved survival: a nationwide observational study in Japan. J Intensive Care. 2018;6:57.

17. Yang Q, Du JL, Shao F. Mortality rate and other clinical features observed in Open vs closed format intensive care units: A systematic review and meta-analysis. Med (Baltim). 2019;98:e16261.

18. De Louw AV, Cohrs A, Leslie D. Incidence of sepsis and associated mortality within the first year after cancer diagnosis in middle aged adults: A US population based study. PLoS One. 2020;15:e0243449.

19. Wang YG, Zhou JC, Wu KS. High 28-day mortality in critically ill patients with sepsis and concomitant active cancer. J Int Med Res. 2018;46:5030-9.

20. Zampieri FG, Salluh JIF, Azevedo LCP, Kahn JM, Damiani LP, Borges LP, et al. ICU staffing feature phenotypes and their relationship with patients' outcomes: an unsupervised machine learning analysis. Intensive Care Med. 2019;45:1599-607.

21. Nassar AP Jr, Zampieri FG, Salluh JI, Bozza FA, Machado FR, Guimarães HP, et al. Organizational factors associated with target sedation on the first $48 \mathrm{~h}$ of mechanical ventilation: an analysis of checklist-ICU database. Crit Care. 2019;23:34. 
22. Danckers M, Grosu H, Jean R, Cruz RB, Fidellaga A, Han Q, et al. Nurse-driven, protocol-directed weaning from mechanical ventilation improves clinical outcomes and is well accepted by intensive care unit physicians. J Crit Care. 2013;28:433-41.

23. Ward NS, Afessa B, Kleinpell R, Tisherman S, Ries M, Howell M, et al. Intensivist/patient ratios in closed ICUs: a statement from the Society of Critical Care Medicine Taskforce on ICU Staffing. Crit Care Med. 2013;41:638-45.

\section{Figures}

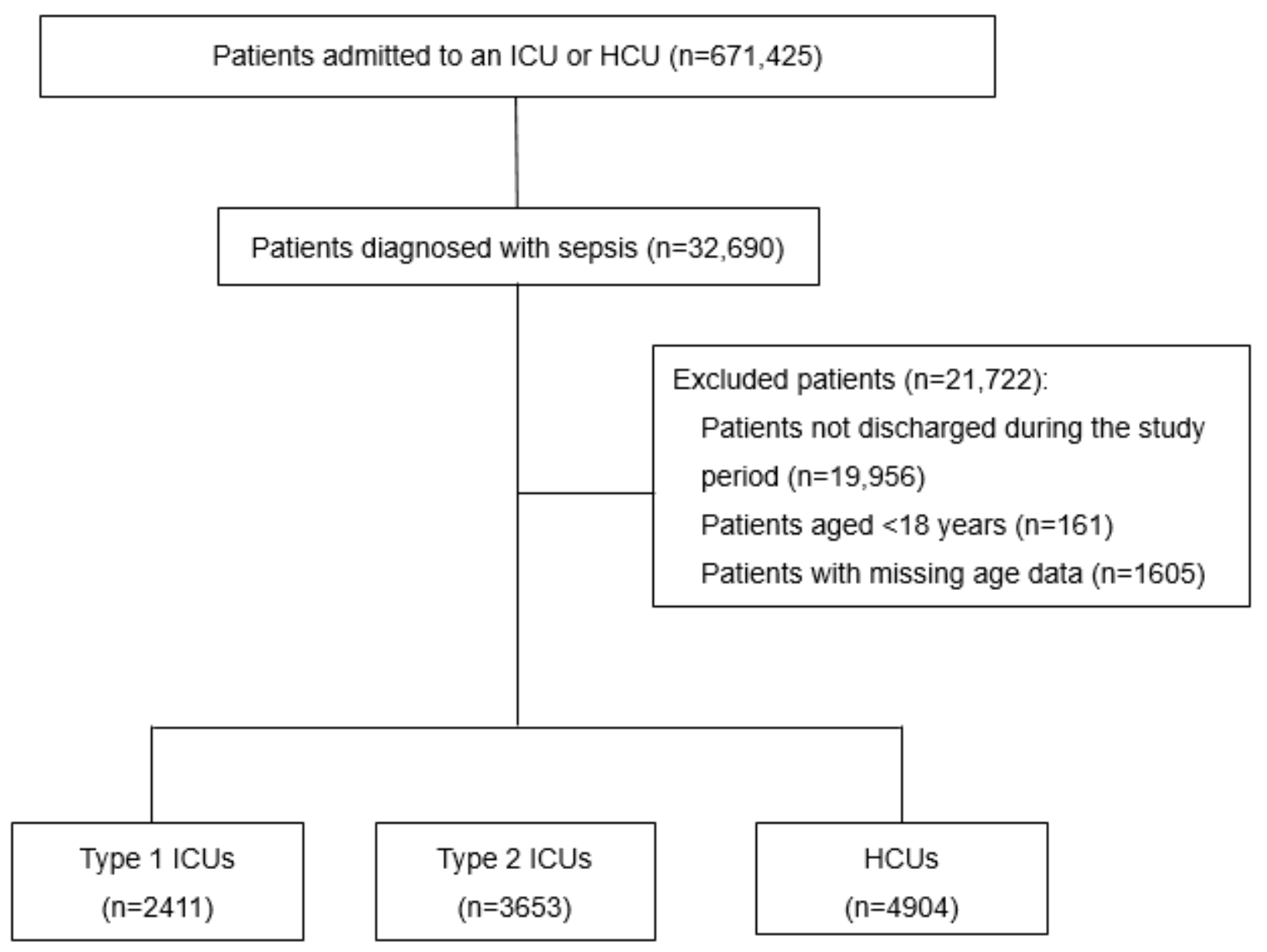

\section{Figure 1}

Flowchart of patient selection ICU intensive care unit; HCU high care unit 


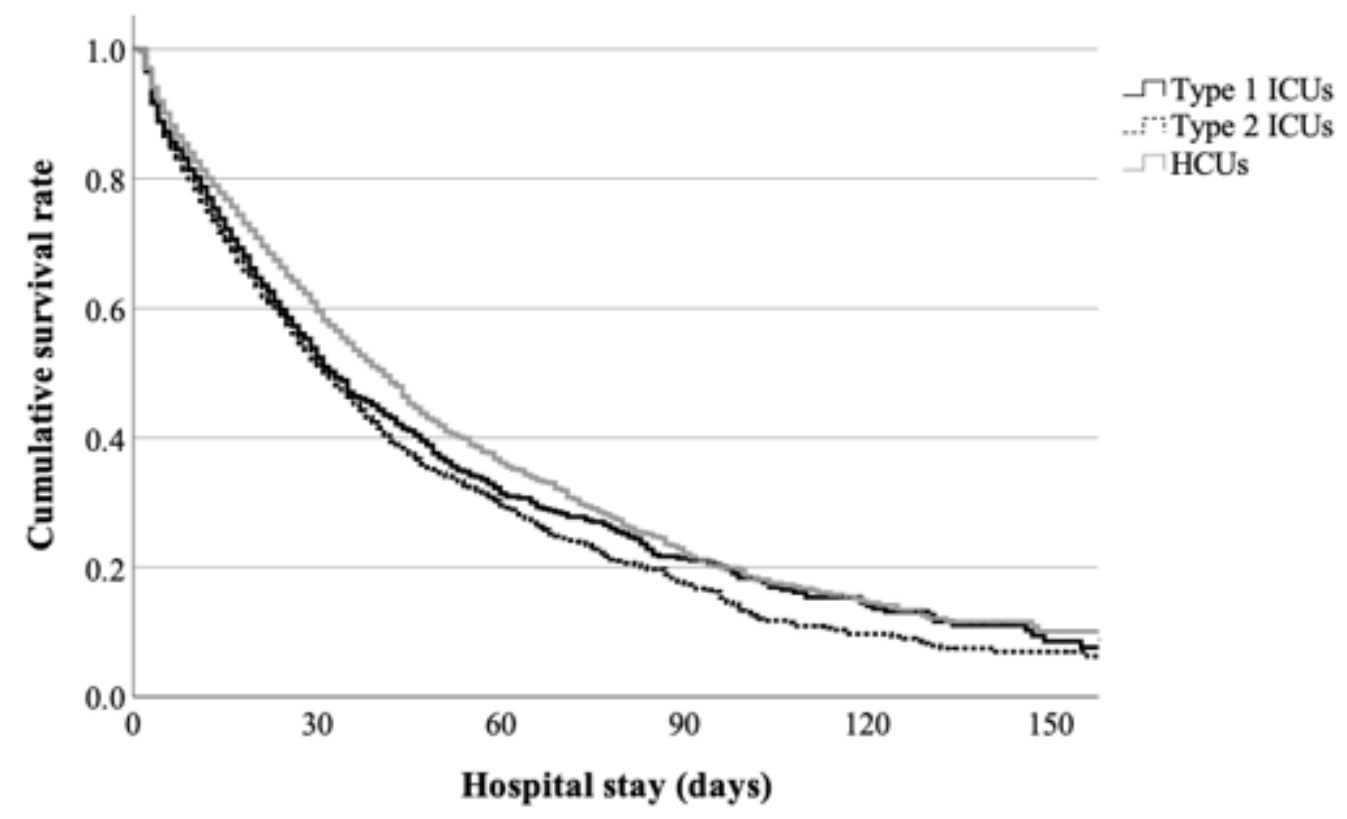

Figure 2

Unadjusted Kaplan-Meier survival curves of the ICU and HCU groups Type 1 ICU group (black line), Type 2 ICU group (black dotted line), and HCU group (gray line). Before adjusting for the covariates, the HCU group had the highest survival rate. ICU intensive care unit; HCU high care unit

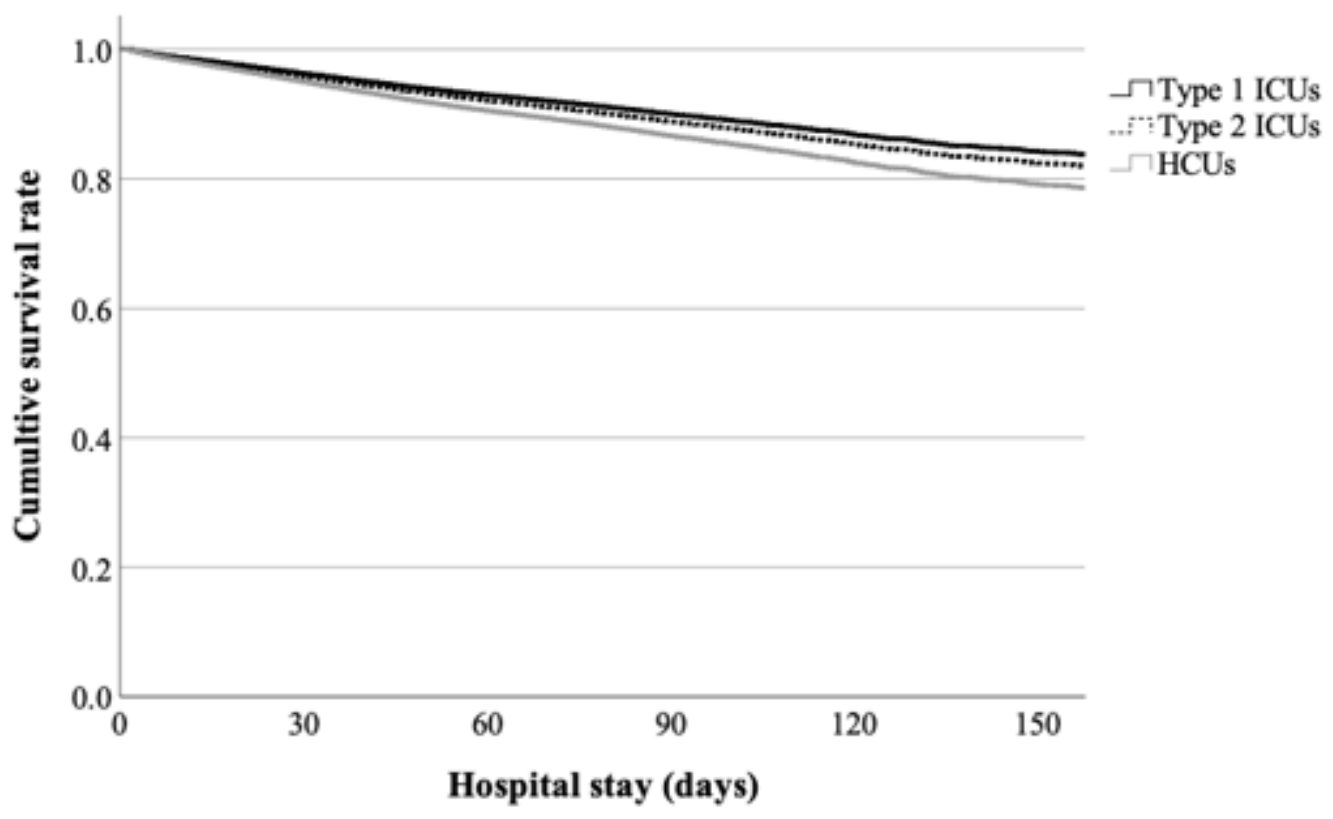

Figure 3

Adjusted Kaplan-Meier survival curves of the ICU and HCU groups Type 1 ICU group (black line), Type 2 ICU group (black dotted line), and HCU group (gray line). After adjusting for the covariates, the Type 1 ICU 
group had the highest survival rate, followed by the Type 2 ICU group. ICU intensive care unit; HCU high care unit

\section{Supplementary Files}

This is a list of supplementary files associated with this preprint. Click to download.

- 20210807Additionalfile1.docx

- 20210809 Graphicalabstractimage.docx 